\title{
АНАЛИЗ ФИНАНСОВОЙ УСТОЙЧИВОСТИ И ЭКОНОМИЧЕСКАЯ БЕЗОПАСНОСТЬ КОМПАНИИ
}

\section{ANALYSIS OF FINANCIAL STABILITY AND ECONOMIC SECURITY OF THE COMPANY}

\section{N. Fedotova}

Summary. The current state of the economy dictates its own laws. On the one hand, this is a high degree of autonomy, on the other hand, there are numerous risks. To preserve the enterprise, it is necessary to strengthen its financial stability. The article shows the relationship between the financial stability of a company and its economic security. When preparing financial decisions, it is necessary to analyze the financial stability of the company, no matter how weaken its security. The analysis of the factors influencing the financial stability of the company has been carried out. The classification of types of financial stability of an enterprise in relation to the external environment in a static environment and dynamics has been carried out. Analyzed the methods that determine the financial stability of the company. The conclusion about the necessity of their application is made.

Keywords: financial sustainability, economic security, financial sustainability, economic security, factor analysis.

\section{Введение}

$\Pi$ од финансовым состоянием принято понимать экономическую категорию, призванную отражать состояние капитала в ходе его кругооборота, и способность экономического субъекта к осуществлению саморазвития на определенный момент времени. Экономико-финансовые условия, в которых экономические субъекты ведут свою деятельность, в современных условиях кардинально изменились, сформулировав целевые установки.

С одной стороны, экономическим субъектам дана хозяйственная автономность, позволяющая в самостоятельном режиме решать вопросы по закупкам и сбыту товаров и услуг, с установлением уровня масштабности производственно-экономической деятельности и способами управления финансовыми средствами. С другой стороны, для таких экономических субъектов свойственно наличие большой степени износа активной части основного капитала, низкое качество производительности трудового процесса, производимых
Федотова Надежда Венедиктовна

К.э.н., аттестованный аудитор, дочент, ФГАОУ «Российский университет транспорта (МИИТ)»

(Москва)

nadejda.fedotowa2012@yandex.ru

Аннотация. Современное состояние экономики диктует свои законы. С одной стороны, это большая степень автономии, с другой стороны, многочисленные риски. Для сохранения предприятия необходимо укреплять его финансовую устойчивость. В статье показана взаимосвязь между финансовой устойчивостью компании и ее экономической безопасностью. При подготовке финансовых решений необходимо анализировать финансовую устойчивость компании, чтобы ни ослабить ее безопасность. Произведен анализ факторов, влияющих на финансовую устойчивость компании. Проведена классификация видов финансовой устойчивости предприятия по отношению к внешней среде в статической среде и динамике. Проанализированы методы, определяющие финансовую устойчивость компании. Сделан вывод об необходимости их применения.

Ключевые слова: финансовая устойчивость, экономическая безопасность, финансовая устойчивость, экономическая безопасность, факторный анализ.

товаров и предоставляемых услуг и как итог - наличие неустойчивых финансовых позиций. К спектру очевидных причин, которые обусловливают возникновение неустойчивых финансовых позиций экономических субъектов, требуется отнести:

1. неудовлетворительную структуру активов экономических субъектов и источников, связанных с их формированием;

2. уменьшение уровня ликвидности баланса экономического субъекта;

3. производство товаров и/или предоставление услуг низкого качества;

4. большая доля просроченной дебиторской и кредиторской задолженностей;

5. малый уровень постоянных пассивов;

6. нарушение положения финансового равновесия, вызывающего возникновение нестабильности, связанной с обеспечением капиталом экономического субъекта;

7. наличие экономически нерациональной структуры и пропорции имущества экономического субъекта и источников его формирования; 


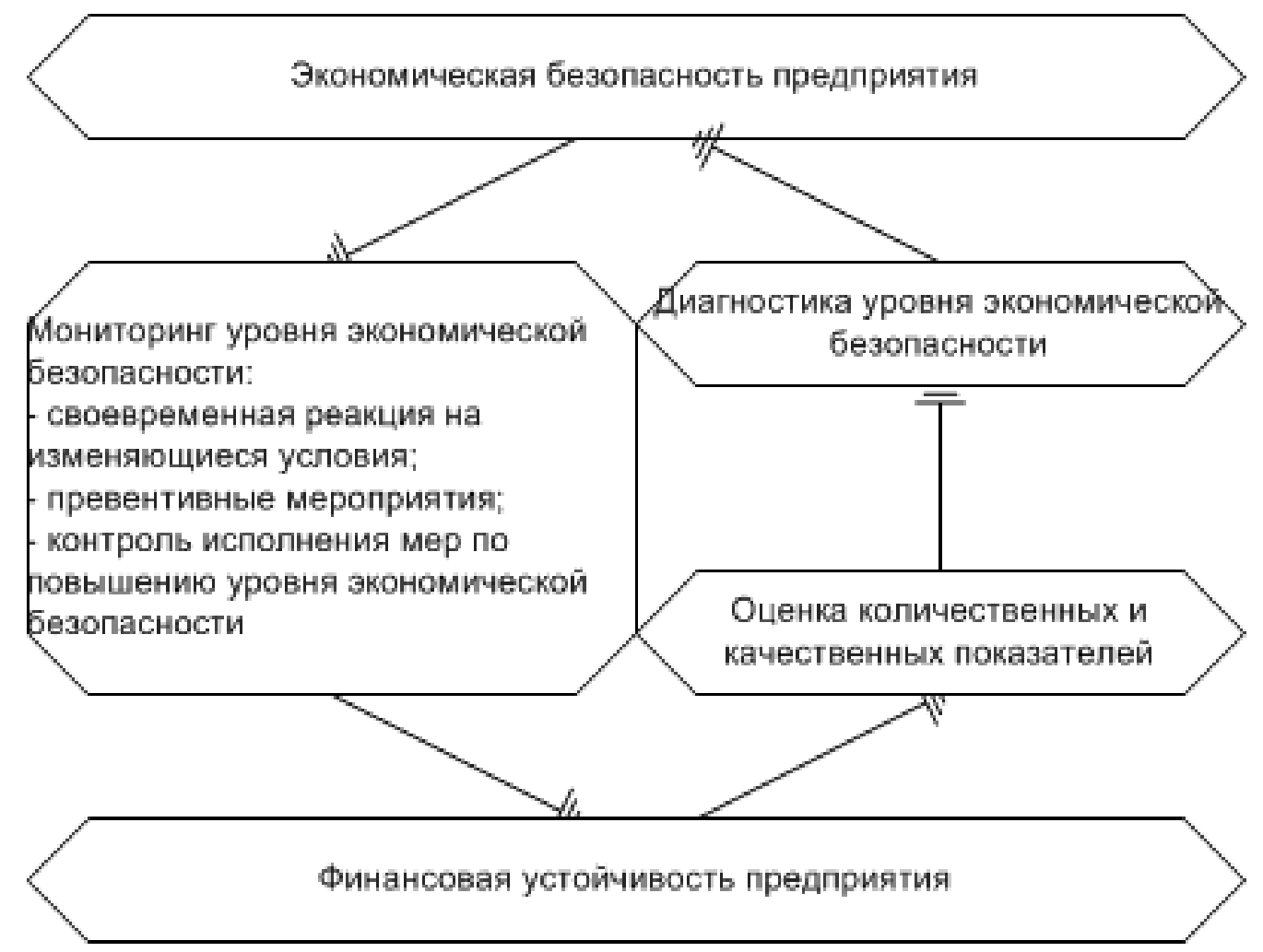

Рис. 1. Взаимосвязь финансовой устойчивости и экономической безопасности субъекта хозяйствования [1]

8. слабый уровень использования хозяйственно-производственных мощностей экономического субъекта.

\section{Финансовая устойчивость компании}

Но основное, чем обусловливается финансовая устойчивость - это текущее финансовое положение компании, а также его возможные перспективы беспрерывного функционирования и развития компании.

Если у компании снижается уровень рентабельности, она становится менее платежеспособной. Изменение финансовых позиций в худшую сторону из-за снижения уровня рентабельности может повлечь за собой наступление и более тяжелых последствий: из-за нехватки денежных средств - уменьшение уровня платежеспособности и ликвидности баланса. Появление при этом кризиса денежной наличности вызывает то, что компания превращается в «потенциально неплатежеспособную», а это может исследоваться в качестве первой ступени кризисного положения (банкротства).

Базис стабильного положения - это его финансовая устойчивость - состояние, связанное с распределением и использованием финансовых ресурсов, обе- спечивающее беспрерывное финансовое равновесие потоков денежных средств и развитие компании в условиях наличия допустимого уровня риска.

Финансовая устойчивость является составной частью и обусловливающим фактором экономической безопасности, их взаимосвязь можно рассмотреть на рис. 1.

Экономическая безопасность организации - защищённость экономических интересов хозяйствующего субъекта от внешних и внутренних угроз, а также создание благоприятных условий для нормального функционирования и устойчивого развития организации.

Проведение анализа и оценки параметров, свидетельствующих об уровне финансовой устойчивости субъектов хозяйствования, дают возможность их менеджерам готовить экономически обоснованные управленческие решения для достижения следующих целей:

- обеспечение финансово-хозяйственной деятельности в бесперебойном режиме;

- способствование развитию исследуемого экономического субъекта на базе долгосрочного прироста суммы прибыли; 
- гарантия непрерывной платёжеспособности в пределах допустимого рискового уровня.

Высокий уровень значимости и роли решений, принимаемых в управленческой сфере, обусловливается их воздействием на все административно-управленческие функции.

Это, в свою очередь, воздействует на финансово-экономическую и рыночную стабильность конкретного субъекта хозяйствования. Под результативным управленческим решением принято понимать решение, подготавливаемое в предельно короткие сроки, способное быть использованным внутри экономического субъекта и принести ему требуемый положительный эффект в виде повышения уровня стабильности функционирования и укрепления параметров финансовой устойчивости на микроуровне [2].

Процесс, связанный с подготовкой управленческих решений в финансовой сфере, предполагает совершение определенного набора управленческих операций со стороны субъекта менеджмента для решения назревших проблем на базе деятельности управляемой системы, а также осуществление анализа данных о её положении. Финансовые решения готовятся согласно набору взаимосвязанных между собой функций и одновременно с этим формирующих непосредственно процесс подготовки конкретного решения. Процесс, связанный с подготовкой управленческих решений в финансовой сфере, включает следующие ниже этапы [3]:

1. Идентифицирование проблемы.

2. Установление перечня критериев, воздействующих на подготовку управленческого решения.

3. Распределение критериев согласно уровню своей важности.

4. Определение прогнозных вариантов.

5. Оценка возможных альтернатив.

6. Выбор предельно наилучшего варианта.

7. Практическая реализация подготовленного управленческого решения.

8. Оценка результативности подготовленного управленческого решения.

Процесс, связанный с подготовкой управленческих решений в финансовой сфере, является элементом управленческого учёта и анализа в виде набора подходов к обработке внутренней информации, поступающей из разных структурных подразделений того или иного субъекта хозяйствования, с целью осуществления контроля и выработки результативных решений [4].

Принятие любых стратегических и тактических решений, необходимых для разработки финансовой политики организации и построения эффективной си- стемы управления, основано на анализе финансового состояния хозяйствующего субъекта, включающего в себя показатели финансовой устойчивости и кредитоспособности.

Как и в любом направлении деятельности реализация интересов организации в экономической сфере происходит в разных условиях и под воздействием со стороны разного набора факторов. Единой позиции по определению и сути факторов финансовой устойчивости и проведению их оценки среди экономистов на современном этапе нет, да и сама категория «финансовая устойчивость» раскрывается в разных вариантах.

Под финансовой устойчивостью организации принято понимать определенное состояние ее счетов, призванное гарантировать постоянную платежеспособность данного экономического субъекта.

По мнению Шеремета А.Д. [5], сутью финансовой устойчивости является обеспечение запасов и затрат формирующими источниками, при этом платежеспособность является её внешним проявлением.

Савицкая Г.В. [6] определяет финансовую устойчивость компании в виде ее способности функционировать и развиваться.

При этом сохраняя равновесие всего перечня активов и пассивов при меняющихся внутренних и внешних факторах для сохранения ее долгосрочной платежеспособности и инвестиционной привлекательности, и при допустимом риске. Следовательно, финансовая устойчивость представляет собой состояние, связанное с распределением и использованием финансовых ресурсов, обеспечивающее беспрерывное финансовое равновесие потоков денежных средств и развитие компании в условиях наличия допустимого уровня риска [7]. На устойчивость того или иного экономического субъекта влияют самые разные факторы, такие как:

1. рыночное положение субъекта хозяйствования;

2. производство дешевых пользующихся потребительским спросом товаров;

3. потенциал субъекта хозяйствования в деловом сотрудничестве;

4. уровень зависимости субъекта хозяйствования от внешних кредиторов и инвесторов;

5. наличие в составе контрагентов неплатежеспособных дебиторов;

6. эффективность экономико-финансовых операций и т.д.

Большое разнообразие факторов обусловливает наличие нескольких видов устойчивости, представленных на рис. 2-3. 


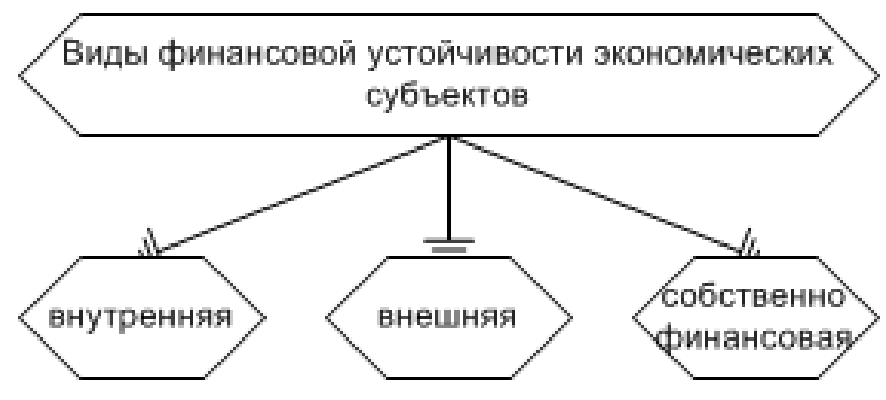

Рис. 2. Виды финансовой устойчивости касательно экономического субъекта

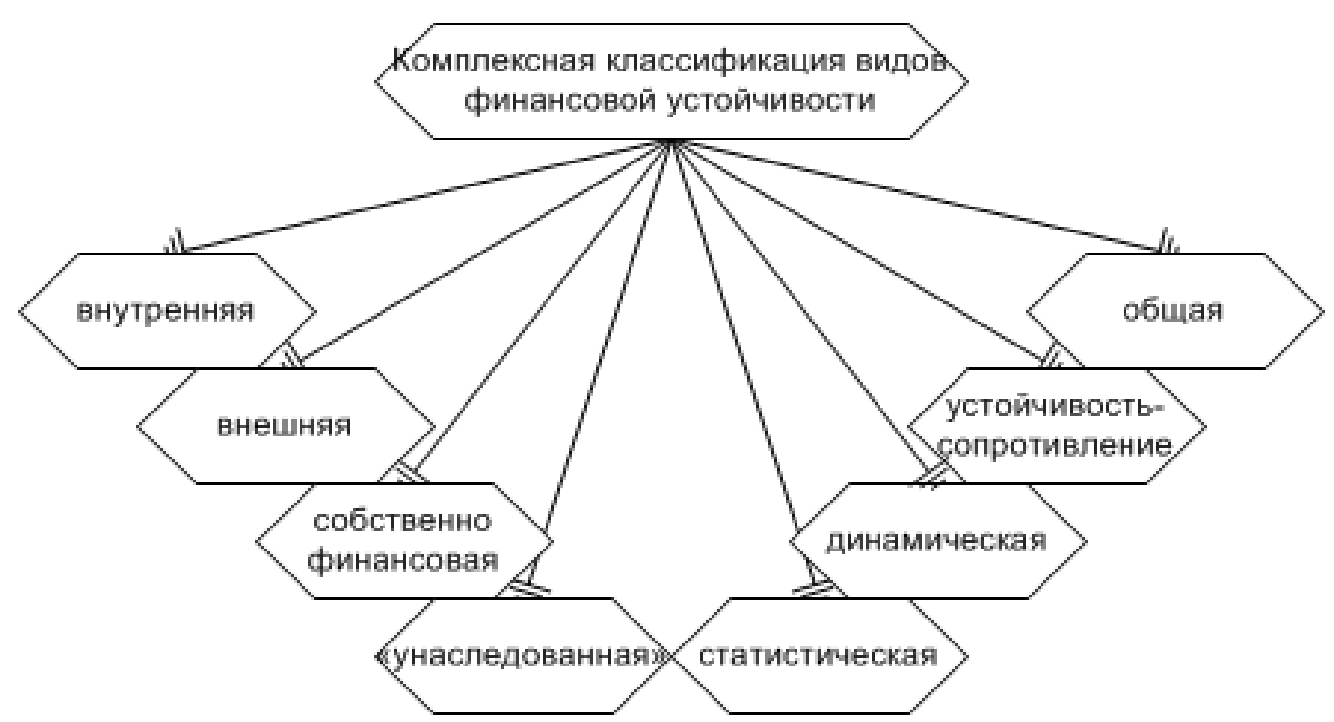

Рис. 3. Комплексная классификация видов финансовой устойчивости предприятия

Например, касательно экономического субъекта она может быть, в зависимости от факторов, принимающих влияние на его экономико-финансовую деятельность, внутренней, внешней, собственно финансовой.

Под внутренней устойчивостью принято понимать общее финансовое положение экономического субъекта, при котором обеспечивается стабильно высокий итог его деятельности. В базисе ее достижения находится принцип активного реагирования на изменение факторов внешней и внутренней среды. Внешняя устойчивость экономического субъекта связана с уровнем стабильности экономической среды, в пределах которой ведется его деятельность. Данный вид устойчивости достигается соответствующей управленческой системой со стороны рыночной экономики в общенациональном масштабе, где функционирует экономический субъект.

Собственно, финансовая устойчивость - это, в первую очередь, степень независимости того или иного экономического субъекта от заемного капитала; уровень обеспеченности активов компании собственными финансовыми ресурсами.

«Унаследованная» устойчивость предприятия выступает в качестве результата наличия определённого уровня запаса его прочности, который призван защитить тот или иной экономический субъект от различного рода случайностей и резких изменений со стороны факторов внешней среды.

В теории и практике финансового менеджмента принято различать также статическую и динамическую устойчивость предприятия.

Понятие статической устойчивости принято отождествлять с понятием покоя или пассивности. Понятие динамической устойчивости предприятия отождествляется с его стабильным финансово-экономическим развитием. Однако практика финансового менеджмента доказала, наивысшая форма устойчивости 
предприятия - это устойчивость-сопротивление. Это состояние достигнутого равновесия экономического субъекта, сохраняющегося, не смотря на влияние факторов внешней и внутренней среды, пытающихся вывести его из данного состояния.

Выделяют еще общую устойчивость предприятия, под которым понимается движение денежных потоков, обеспечивающее превышение сумм доходов над суммами расходов в постоянном режиме.

Установление отношений делового характера с неустойчивым (с финансовой точки зрения) партнером может обернуться срывом процесса производства товаров (выполнения работ, оказания услуг) по причине несвоевременной поставки сырья. Как итог - простои и обусловленное этим несение дополнительных затрат.

В условиях современного финансово-экономического кризиса не каждая компания сможет выдержать несение дополнительных издержек.

По причине чего особую актуальность получают системы параметров, дающих возможность максимально точно определить уровень финансовой устойчивости потенциального бизнес-партнера и, следовательно, уменьшить уровень риска, связанного с установлением деловых отношений с финансовой точки зрения неустойчивым контрагентом.

Проведение анализа финансовой отчетности того или иного экономического субъекта дает возможность получить ответы на следующие вопросы:

- в какой степени компания независима с финансовой точки зрения;

- являются ли финансовые позиции компании устойчивым.

Принцип финансовой устойчивости означает такую экономико-финансовую деятельность экономического субъекта, при которой он в состоянии был бы в любой временной отрезок покрыть свои долги или собственными финансовыми ресурсами или благодаря получению отсрочки, или с помощью получения кредитного капитала. Финансовая устойчивость того или иного экономического субъекта будет зависеть от влияния большого количества всевозможного набора факто- ров. Широкое многообразие аспектов потребует их классификации следующим образом:

1. по месту появления - PESTLE-факторы и SWOT-факторы;

2. по важности итога - факторы главного и второстепенного характера;

3. по структуре - простые и сложные факторы;

4. по длительности действия - постоянные и временные факторы.

K SWOT-факторам (факторы внутренней среды), оказывающим влияние на финансовое состояние того или иного экономического субъекта, относятся:

1. принадлежность отраслевого характера экономического субъекта;

2. структура производимых товаров (выполняемых работ, оказываемых услуг), их удельный вес в совокупном платежеспособном потребительском спросе;

3. размер уставного фонда;

4. сумма затрат, их динамика относительно изменения величины денежных доходов;

5. состояние активов и источников их формирования.

K PESTLE-факторам (факторы внешней среды) принято относить следующие:

1. экономико-финансовые условий деятельности;

2. главенствующая в социуме технология и техника;

3. степень платежеспособного спроса и потребительских доходов населения;

4. налоговая и кредитно-финансовая политика Правительства Российской Федерации;

5. нормативно-правовые акты, призванные регулировать бизнес-деятельность компании;

6. внешнехозяйственные связи;

7. система общественных ценностей и т.д.

\section{Зак^ючение}

Безопасность компании зависит от ее финансовой устойчивости. Анализ факторов, влияющих на устойчивость компании, необходимо производить при принятии любых управленческих решений.

Обеспечение финансовой устойчивости и ее поддержание является сложным менеджерским процессом стабильного развития экономического субъекта.

\section{ЛИТЕРАТУРА}

1. Авдеева В.И. Финансовый менеджмент: учебник / В.И. Авдеева, 0.И. Костина, Н.Н. Губернаторова. -М.: КНОРуС, 2017.-384, с. 6

2. Бариленко В.И. Анализ финансовой отчетности: учебное пособие / коллектив авторов; под общ. ред. В.И. Бариленко.- 4-е изд., перераб.- М.: KHOPУC, 2016. - 234 c., c. 7 
3. Володин А.А. Управление финансами. Финансы предприятий: Учебник / А.А. Володин, Н.Ф. Самсонов, Л.А. Бурмистрова, Л.В. Смирнова, А.А. Тилов, Л.В. Токун, М.Б. Траченко; Под ред. А.А. Володина. - 3-е изд.- М.: НИЦ ИНФРА-М, 2019. - 364 с., с. 8

4. Гарнов А.П. Анализ и диагностика финансово-хозяйственной деятельности предприятия: учебник / под ред. А.П. Гарнова. - М.: ИНФРА-М, 2018. 366 c., c. 8

5. Шеремет А.Д. Теория экономического анализа: учебник / А.Д. Шеремет, А.Н. Хорин. — 4-е изд., доп. — М.: ИНФРА-М, 2019. — 389 с., с. 7

6. Савицкая Г.В. Анализ хозяйственной деятельности: учебное пособие / Г.В. Савицкая.— 6-е изд., испр. и доп.— М.: ИНФРА-М, 2019.— 284 с., с. 7

7. Герасимова В.Д. Анализ и диагностика финансово-хозяйственной деятельности промышленного предприятия: учебное пособие / В.Д. Герасимова, А.А. Прохоренко, И.В. М.: Кнорус, 2017.-358с., с. 8

( Федотова Надежда Венедиктовна ( nadejda.fedotowa2012@yandex.ru ).

Журнал «Современная наука: актуальные проблемы теории и практики»

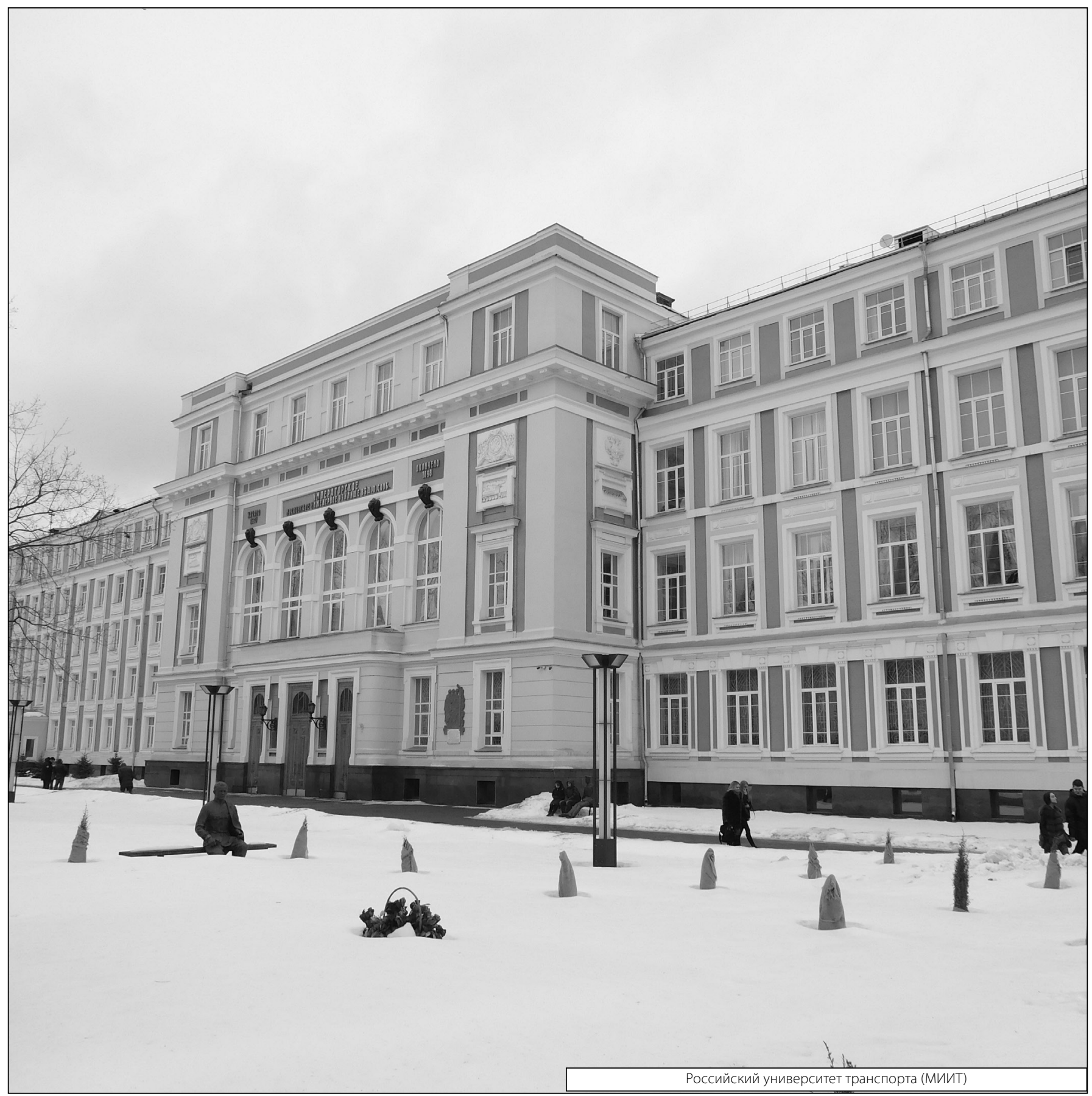

